\title{
The Impact of Political Instability on the Economic Growth: An Empirical Analysis for the Case of Selected Arab Countries
}

\author{
Khadiga Elbargathi*, Ghazi Al-Assaf \\ Business Economics Department, Faculty of Business, University of Jordan, Amman, Jordan \\ Email address: \\ k_albargathi@yahoo.com (K. Elbargathi), g.alassaf@ju.edu.jo (G. Al-Assaf) \\ *Corresponding author
}

\section{To cite this article:}

Khadiga Elbargathi, Ghazi Al-Assaf. The Impact of Political Instability on the Economic Growth: An Empirical Analysis for the Case of Selected Arab Countries. International Journal of Business and Economics Research. Vol. 8, No. 1, 2019, pp. 14-22. doi: 10.11648/j.ijber.20190801.13

Received: January 2, 2019; Accepted: January 24, 20198; Published: February 21, 2019

\begin{abstract}
This study investigates the impact of political instability on the economic growth in Egypt, Jordan, Lebanon, and Tunisia for the period of 1996-2016. The study examines the existence of the long-run relationship between different five political indicators and the growth of the economy. The study utilized panel data analysis, using annual data covering the period of 1996-2016, for the four selected Arab countries. The empirical results of the study, using the Vector Error Correction Model (VECM), highlight the impact of different political instability indicators on economic growth. Moreover, these results indicate that there is a strong long-run relationship between the several political indicators upon the economic growth. More specifically, the results show that the control of the corruption and the rule of law indicators have the highest impact on the economic growth, while the regulatory quality has the lowest.
\end{abstract}

Keywords: Political Instability, Economic Growth, Arab Countries, Panel Cointegration

\section{Introduction}

The world in general constantly faces economic and political transpositions. In particular, several economic cycles of Arab countries have witnessed satisfied movements, while others have remained poor and declined according to the huge numbers of their citizens. Alternatively, political stability plays a remarkable role in the country's economic evolution; as the stability of the government system, which can be achieved through low rates of structural and economic changes; provides a comfortable environment which enhances the investors and economists to practice and execute their activities. While an instable political system could seriously restrain all of the above and hinder economic efficiency.

No doubt, Arab spring was one of the unprecedented seasons in the Arab world; which resulted in an unforgettable experience for all Arab societies. The revolution in Tunisia was the spark in 2011, which gave the green light to other Arab countries such as Egypt, Libya, Syria, and Yemen to follow the same steps [1].

Modern theories of political economy propose that political instability (PI) dominates the economics of many Arab countries, therefore, the presence of the fluctuating in the policy decisions and goals consider as poor indicator to the government of such a country; as it has been stated in the theoretical framework of the modernistic economy, as a result, this kind of unsecured government can be a cause of domestic troubles, which indirectly can influence the economic outcomes in the country through the linkage among the economic efficacy rates, and the current policies, in addition to the way of how the polity implement them [2]. Moreover, the positive alteration in the country's economy accomplished by the welfare policies and the improvement priorities that governments set for their society. In brief, where there is good politics there is good economics.

The connection between PI and macroeconomic variables still remains in the center of the scholarly debates since it is one of the continuing relationships in the social and political economies. Furthermore, this type of correlation has been an 
issue of concern for a long time; because the empirical studies revealed different findings for different regions, different countries, and for different periods.

In the present, there have been abundant of paradoxical negotiations when multiple and sundry estimations related to the association between political indicators and economic variables have been predicted. Although the political risks consider as a key obstacle to economic activities, however, so many firms keep investing in instable countries environments, these forecasted results are divided between positive relationships; as proved by the discussion of Bueno about the instability; as the latter enhances the policy ideas competition, which will lead to efficient government policies implementation and will have an indirect positive impact on economic growth [3]. Moreover, the negativity hypothesis, which has been supported by the majority of scholarly; PI, in general, is bad for economic efficiency [4]. In conclusion, several researchers in the field have yielded highly different findings, and still, no agreement has been reached as to what this relationship really looks like.

Such antithetical findings suggest the need for further thinking about the links between PI and these variables in many countries. Therefore, capturing the interest of this paper had been extracted from this controversy, as well as from the investigation the way of how the measured indicators can influence the economic consequence, as it has been a primary issue for both theoretical and empirical concerns.

The purpose of the research is to examine the nature of the serious problems such as PI upon the economic growth at the macro level, for different developing Arab countries such as Jordan, Egypt, Lebanon, and Tunisia, during the period of 1996-2016; whenever the relevant data is available.

The answer to the question of whether political indicators might affect the performance of economic growth can be obtained from cointegration analysis, which could be implemented using various cointegration methodologies.

The main contribution of this study is to fill the gap that has been found in the literature review, as few relevant studies have focused on the comparative between the political indicators and their impact on the economic growth, through the time period it covers which is crucial; as it reflects the recent political circumstances have happened in the chosen countries, additionally, it will provide an empirical application for a sample contains more than one Arabic country rather than investigation just one small country at the corner of the world knowing that the light in the preceding literature has been spotted on non-Arab countries.

The paper continuous as follows: section two discussed the main literature review, section three describes the dataset and presents the empirical methodology, section four explains the empirical results, and section five concludes the paper.

\section{Review of Literature}

There have been a plentiful of previous studies which covered this topic from different angles, but only in the last few years the modern research started to apply and involve the political indicators as the study variables.

The relevant literature has discussed the association between PI and the growth of the economy; although all the pertinent prior studies had tested the similar common factor which was the economic growth, the findings were antithetical and diverged. In other word, the relationship between PI and growth has been divided into different categories.

Alesina, Alberto, and Roberto examined the association between PI and per capita GDP growth by using government collapse as an instable indicator, with a sample of 113 countries during the period 1950-1982. The findings stated that the country with a high amount of government breaks down, suffered from low rates of economic growth [5].

Feng developed a theoretical framework to represent the connection between the three disciples; political stability, the foundations of democracy and economic growth of any functioning economic system. The connection is however established through two different approaches. The first approaches take a simpler pattern where democracy and growth are paired together, and in the next group, growth is paired with political instability. And then the results of both the groups are compared to see if political instability is kept stagnant, then which factor is likely to progress more in terms of forming a positive or a negative relation. The second approach is more detailed. It includes studying different forms of political instability. Also, this approach has been critically analyzed to see other varying factors that can be seen when the governments change. These changes impact both growth and democracy in more than one ways. The data for this study was taken from the years 1960-1980 with total involvement of 96 nations in all [6]. The final results of the study revealed that democracy and economic growth did share a positive relation with each other and that other factors are variant. They can change over the transformation of political scenarios and shifts in government regimes. In the longer run, the political situation in terms of a stable environment has a positive effect on the macroeconomic variables and this increases the probability of economic growth.

Surprisingly, Campos \& Nugent found unexpected results when he conducted a research paper to investigate the adverse long-run correlation between PI economic growth. No significant relationship was the main outcomes of the above study [7].

Zureiqat used more than seventeen observations of around 25 countries from Africa, Central and Eastern Europe, Latin America, the Middle East, and Southeast Asia, was the sample of this study. Moreover, testing the impact of PI on the growth of GDP per capita in the chosen countries was the main purpose to be investigated. The results confirmed that the measured instable indicators have a significant relationship with the growth of the economies of these countries [8].

Farida \& Ahmadi, explored the influence of corruption as a political instability indictor on the economic growth in Lebanon, using a neoclassical model. The hypothesis of the study was the corruption decreases the standard of living as measured by real per capita GDP. The results revealed that corruption has an adversely indirect effect on the GDP in 
Lebanon, through the lack of government expenditure efficiencies and the reduction in investment and human capital productivity [9].

Aisen \& Veiga examined how political instability affects the economic growth and progress of an economy. For this purpose, the authors used the GMM estimator to examine data from 169 nations over a five year period spanning from 1960-2004. One reason that the study found was that political instability was also dependent upon the rates of gross domestic product in the economy. The lower the rate of the gross domestic product, the higher the chances for the political situations to become instable. In a similar scenario, political instability could affect the constituent factors of growth in a number of ways. These range from decreased rates of productivity, the effect on smaller business and labor and employment rates etc. It was also noted that even a democratic state but with high rates of political uprisings could do little for the economy of a nation in case of instable political environments [10].

Ali \& Rehman started the research with a simple question that whether macroeconomic factors impacted the stability of the Pakistani economy. In this relation, the gross domestic product of the nation was studied from data spanning from 1980-2012. For this purpose, the macroeconomic instability index was constructed using the variants; inflation rate, unemployment rate, budget and trade deficits. The involved model was the Autoregressive Distributed Lag Model with the addition of the Vector Correction Model, to find the co-relation between the variants. The third tool that was used was the Granger Causality Test to determine which variables affected the others in order to cause a significant change in the instability index. The results of the tests concluded that indeed, there was the existence of a powerful relation between the gross domestic product of Pakistan and the macroeconomic instability. It was further established that because of fluctuations in the values of the macroeconomic variables, economic instability existed and this, in turn, affected the gross domestic product and other variants for the nation. The investigators for this paper recommended the government to place emphasis on policies to make the economic environment more stable and less hostile to the internal political situation so that there is little fluctuation [11].

Different economics have adversely impacted by the consequences of the Arab Spring, in this regard, Abdelkader, used time-series data for the period 1972 to 2013 in Egypt, in order to investigate the association between political instability, uncertainty, and political regime, in addition to the economic growth as well [12]. Therefore, a GARCH model approach is used in the Error-Correction Model (ECM) to introduce the uncertainty impact, Pesaran's bound test is employed to confirm the results. Finally, the cointegration approach applied to figure out the short- and long-run of the relationships. Although the findings confirmed the positive and negative impact represented by the level of the democracy and the uncertainty respectively, the effect of PI on the economic growth was not clear and could not be clarified yet. Accordingly, Matta \& Bleaney wrote a paper to predict the
GDP loss in Tunisia by using Synthetic Control Methodology, and Results asserted the declining in GDP was (5.5\%) in $2011(5.1 \%)$ in 2012 , and $(6.4 \%)$ in 2013 . In addition, the study found that the high level of the inverse impact by Arab Spring was on the investment sector in Tunisia [13].

The adverse effect of the political instability on the economic growth can be seen also Jordan as proved by Sweidan, as it has been suffered from a different political deficit in the past. Investigation the correlation between PI and the economic growth in Jordan was the main purpose of this paper. The author applied the ARDL model (OLS) and Kalman filter for the period 1967-2009, [14].

Although Kaplan \& Akçoraoğlu applied the same econometrical tool to analyze the exact policy indicators used by Aisen \& Veiga; various and similar interpretations have shown up in the results of this study. The sample of this study was Organization for Economic Co-operation and Development (OECD) countries, more than 28 countries were conducted using data during 1984 - 2012. The results also found that PI has a negative impact on the growth levels. While democracy had no significant impact on the growth of such countries [15].

As the riskiness and the negative consequences of the political conflicts reach and disturb all the economic aspects, it is good to mention how this issue handled and covered by previous papers. Ari Aisen, who works for the International Monetary Fund, and other author have discussed this relationship between PI and the inflation in different countries, and the results were as the following:

Aisen \& Veiga measured and tested a cross-sectional data for more than 90 countries approximately, for the years from 1960 to 1999 in order to figure out the reasons of the volatility of the inflation rates around the world. After using advanced econometric tools and methods, the instability of the policies of the country was one of the main causes of the fluctuating in the inflation levels [16].

In addition to the latter paper, same authors in the same year conducted a second one but touched the topic from a different angle. The main objective of this study was to understand why the inflation disperse from one country to another? Many answers elaborated this inquiry, but the dominant reason was PI [16]. Also, Khan \& Saqib focused on the impact of PI on inflation in Pakistan, for the period of 1951-2007 and Generalized Method of Moments applied to investigate the relation between these two variables. The findings confirmed that the lack of stability in the country policies results to a high degree of inflation levels [17].

Najaf tried to explain the relationship between political stability and the macroeconomic variables. This also includes the foreign domestic investments, which inflation hold an important position in reference to the economy of Pakistan. The research for this paper has been conducted after taking into account the statistics from the period 1991-2011 [18]. The Augmented Dickey-Fuller Test was utilized to understand the correlation between the two factors of the study. It was also used to assess how stationary or stagnant were the variables during the two decades that were chosen. The indications of 
the study concluded that the foreign direct investment is dependent upon the imports of the nation, the balance of payments and the gross domestic product of the economy. It was further noted that the rate of inflation and foreign domestic investments formed a negative relation, therefore political stability did not play a significant role in the expansion or economic growth of the nation's economy.

Alternatively, the interconnection between political instability and the fixed capital formation has been investigated by a number of researchers, and different findings and conclusion have been raised regarding this issue. Asiedu studied the final conclusions of the primary studies that have been conducted before. The premise of these studies suggested that the effect of variants such as investments, political and macroeconomic instability, and domestic political uprisings posed a threat to the foreign direct investments in the nation of Africa. The data of over 22 nations were collected from the period from 1984-2000. However, the main dimensions of explanation were thoroughly different in comparison to that of this study. It was determined that foreign direct investments in any nation depend upon that country's political stability, how valuable the natural resources of a nation are, the size of the market, the internal governmental policies and conflicts and the current situation of investments in the nation. With these factors being stable enough, the nation can then receive a steady flow of foreign investments. The results of this study were sufficient enough to prove that South Africa could receive economic growth if it provides a supportive political environment for the economy to grow in the long run [19].

Tosun, Guran \& Ulucan aimed to investigate the factors that determine the level of investments in the Middle Eastern and North African regions. The main focus of the paper was to see how the political instability in these areas of the world affected the performance of the macroeconomic agents. A detailed analysis was published with basic emphasis laid on the level of inflations, potential economic growth of the regions, the growth rates, the trends of the balance of payments (with the incurring profits and losses). For this purpose, the study used the Malmquist Productivity Index especially for the regions that fall under the provisions of MENA including Turkey. The study evaluated data from the years 1987-2003. The authors further explained through this study that the marked regions were given critical importance since the Gulf War enabled sharp declines in the economic performances of these regions. It was concluded that for these regions and with the advent of the Gulf War, a negative relation was found to exist between the political hostility and risks, and the performance of macroeconomic variables [20].

Furthermore, even though the general interpretation of the relation between uncertainty and the accumulation of the physical capital is summarized as simple as that; the higher the instability the lower the investment, the proper effect and the direction of the causality between both variables have not been clarified yet. In this regards, Campos \& Nugent, have tested this correlation and surprisingly, the finding approved that policy instability has a positive long term effect on the investment especially in countries with low income levels. This results agreed and confirmed with another previous research that conducted the Shell oil company in Nigeria as the case of the study, notably that the World Bank classified Nigeria as a lower income country [21]. Frynas analyzed the status of the company and reached a conclusion of regardless how much Nigeria suffers from the instability in their business environment, the investing and working plans for Shell companies are still increasing in such a country and generating high profits [22].

To summarize and after all the above, most of the findings from the primary and secondary research data indicate that the economic progress and future growth is dependent upon the stability of the political scenario of a nation. On the other hand several results revealed that macroeconomic variables are not closely related to the political situation and slowly affected by any changes in the form of chaos or internal and external conflicts.

In conclusion, unfortunately, the nature of the impact that the policy deficits have on the economic activities has not been cleared yet. Correspondingly the studies concerning this issue are rich in the case of some countries but are not for other developing countries. Therefore, the value added of this study is to bridge between what it has been found missing in the literature.

\section{Methodology and Model Specification}

\subsection{Data Source}

The source of political and institutional data is the Worldwide Governance Indicators (WGI) which produced by Natural Resource Governance Institute (NRGI), Brookings Institution and World Bank Development Research Group [23]. It reports aggregate and individual governance indicators for more than 200 countries since the late 1990s.

Furthermore, the annual data on economic variables were gathered for the selected countries from the World Bank's World Development Indicators (WDI).

The sample consists of Egypt, Jordan, Lebanon, and Tunisia. Selecting such countries is based on data availability, also as it has been stated that the above countries have suffered from some political instability during the period under investigation which covers 1996 - 2016 such as; Arab spring situations, fluctuations in countries' regulations and policies, the cabinet changes, and corruptions.

\subsection{The Econometric Model}

The model based on economic theory and previous empirical studies such as Zureiqat [8], will be estimated in order to achieve the study objectives and the main study hypothesis. To analyze the impact of political instability on economic growth, such the following is used:

$$
\text { GGDPt }=\beta 0+\beta 1 \mathrm{LGFCFt}+\beta 2 \mathrm{LHCt}+\beta 3 \text { PIit }+\varepsilon \mathrm{t}
$$

Where:

GGDP: GDP per capita growth (annual \%). 
LGFCF: the natural logarithm of the gross fixed capital formation.

LHC: the natural logarithm of the human capital.

$\mathrm{PI}_{\mathrm{i}}$ : several political instability indicators, which include: voice and accountability (VA), political stability and absence of violence/terrorism (PV), regulatory quality (RQ), rule of law (RL), and control of corruption (CC).

$\beta 1, \ldots, \beta 4$ : the estimated parameters for the independent variables.

$\varepsilon$ : The error term.

\subsection{Study Hypotheses}

$\mathrm{H}_{0}$ : There is no significant impact of political instability on the economic growth in Jordan, Egypt, Lebanon, and Tunisia.

\subsection{Study Variables Definition}

The following variables are used in this paper as dependent and independent variables. The dependent variable is the economic growth. While the independent once are the political instability indicators in addition to several other explanatory variables that effect the dependent variables.

WGI has defined the governance as "the values, mores, and foundations which implemented by the polity of the country". This definition covered three different governance areas and several corresponding measures have been developed to examine each area:

1. The approach of how the governments are chosen, observed and substituted; measured by Voice and Accountability (VA) and Political Stability and Absence of Violence/Terrorism (PV).

2. The government ability to address and applied relevant policies; measured by Regulatory Quality (RQ).

3 . The degree of the respect of the country and their societies for the organizations that responsible for economic and social activities; measured by Rule of Law (RL) and Control of Corruption (CC) [23].

On the other hand, the economic growth of a nation is dependent upon several indicators that form the basis of the term. An increase in the value of production of goods and services, lower rates of inflation, higher paces of investment and more 0employment are some of the virtues that define how the economy is holding its ground [24]. Also, Economic growth is defined as the relative increase in gross domestic product (GDP), measured by fixed prices over a period of time. Additionally, it can be known as the real increase in GDP per capita during a specific time [25]. Correspondingly, according to the World Bank, it can be considered is a welfare indicator and one of the standard of living measurements [26].

Furthermore, investment is regarded as the injection of capital or monetary assets into a venture with the intention of making profits. Also, investments are one of the most integral components of an economic system, where more and more of these injections define the position of a nation [27]. World Bank has stated clear content of the Gross fixed capital formation, such as the land development, and the purchasing of plants, machinery, and equipment, in addition to the restructure and improvements of public and private buildings [26].

The human capital is defined as all the skills and abilities embodied in the working individual or the labor force acquired through training, education, health care, or good food quality. And for the purposes of the economic analysis, this variable expressed by the total labor force that contributing to producing the goods and the services [26].

\section{The Empirical Results}

This section presents the empirical portion of the study; where the data related to Egypt, Jordan, Lebanon, and Tunisia will be analyzed by conducting the necessary econometrics tests through Panel Cointegration Analysis. Firstly is to test the stationarity of each variable using panel unit root tests, then to examine the long run relationship between the study variables and finally, based on the results of point 1 and 2, a proper method of estimation will be chosen.

\subsection{Panel Unit Root Tests}

In order to identify the degree of integration of the basic variables in the model, several panel unit root tests were conducted to determine the degree of the stationary of the cross-sectional data, as a first step to avoid the spurious regression. In this regard, Im, Pesran \& Shin (IPS), ADF Fisher Chi-square (ADF) and PP - Fisher Chi-square (PP) were used to test the stationary of the data at the level and the first difference. The general hypotheses of the panel unit root tests are:

$\mathrm{H}_{0}$ : Panel data has a unit root (non-stationary).

$\mathrm{H}_{1}$ : Panel data does not have a unit root (stationary).

Tables 1, 2, 3 and 4 show the results of the applied panel unit root tests. Correspondingly, the results revealed that most of the data were not stationary at the level but the majority of the data became stationary after taking the $1^{\text {st }}$ difference.

Table 1. Panel unit root test: Level (Individual intercept).

\begin{tabular}{lllllllll}
\hline Variables/Tests & GGDP & LGFCF & LHC & VA & PV & RQ & RL \\
\hline IPS & 0.3459 & 0.9002 & 0.9589 & 0.1339 & 0.9245 & 0.8655 \\
ADF & 0.4625 & 0.9570 & 0.9034 & 0.1033 & 0.9212 & 0.7113 & 0.6664 \\
PP & 0.0981 & 0.9490 & 0.9049 & 0.1601 & 0.9126 & 0.3359 & 0.3885 \\
\hline
\end{tabular}

Source: Authors calculation using Eviews. * The numbers presented in the table are the P-values. 
Table 2. Panel unit root test: Level (Individual intercept and trend).

\begin{tabular}{|c|c|c|c|c|c|c|c|c|}
\hline $\begin{array}{l}\text { Variables/ } \\
\text { Tests }\end{array}$ & GGDP & LGFCF & LHC & VA & PV & RQ & RL & $\mathrm{CC}$ \\
\hline IPS & 0.5011 & 0.6839 & 0.0916 & 0.076 & 0.2129 & 0.658 & 0.4633 & 0.1152 \\
\hline $\mathrm{ADF}$ & 0.5915 & 0.623 & 0.0055 & 0.0529 & 0.2127 & 0.2714 & 0.5122 & 0.1509 \\
\hline PP & 0.1386 & 0.8717 & 0.9869 & 0.3065 & 0.0676 & 0.1479 & 0.6154 & 0.0216 \\
\hline
\end{tabular}

Source: Authors calculation using Eviews. * The numbers presented in the table are the P-values.

Table 3. Panel unit root test: $1^{\text {st }}$ difference (Individual intercept).

\begin{tabular}{lllllllll}
\hline Variables/ & GGDP & LGFCF & LHC & VA & PV & RQ & RL & CC \\
\hline Tests & & & & & & & & 0.00003 \\
IPS & 0.0012 & 0.0401 & 0.0093 & 0.0000 & 0.0013 & 0.0000 & 0.0003 & 0.0000 \\
ADF & 0.0022 & 0.0548 & 0.0082 & 0.0000 & 0.0028 & 0.0001 & 0.001 & 0.0000 \\
PP & 0.0000 & 0.0101 & 0.0133 & 0.0000 & 0.0000 & 0.0000 & 0.0000 & 0.0000 \\
\hline
\end{tabular}

Source: Authors calculation using Eviews. * The numbers presented in the table are the P-values.

Table 4. Panel unit root test: $1^{\text {st }}$ difference (Individual intercept and trend).

\begin{tabular}{|c|c|c|c|c|c|c|c|c|}
\hline $\begin{array}{l}\text { Variables/ } \\
\text { Tests }\end{array}$ & GGDP & LGFCF & LHC & VA & PV & RQ & $\mathbf{R L}$ & $\mathrm{CC}$ \\
\hline IPS & 0.068 & 0.3032 & 0.0477 & 0.0000 & 0.0242 & 0.0004 & 0.0093 & 0.0000 \\
\hline $\mathrm{ADF}$ & 0.0645 & 0.3738 & 0.0308 & 0.0002 & 0.0297 & 0.0014 & 0.0166 & 0.0000 \\
\hline PP & 0.0000 & 0.1342 & 0.0308 & 0.0000 & 0.0000 & 0.0000 & 0.0001 & 0.0000 \\
\hline
\end{tabular}

Source: Authors calculation using Eviews. * The numbers presented in the table are the P-values.

\subsection{Panel Cointegration Test}

In order to investigate whether there is a long relationship among the study variables or not; Kao Panel Cointegration test will be applied. This test is based on the Engle-Granger test, is used with the individual intercept. The general hypothesis for Kao test is:

$\mathrm{H}_{0}$ : There is no cointegration in the model.

$\mathrm{H}_{1}$ : There is a cointegration in the model.

If the probability value is less than $5 \%$ this allows the rejection of the null hypothesis, which means the variables are cointegrated. Alternatively, if it is greater than 5\% this prevents the rejection of the null hypothesis. In the present case, the value of the probability for the model is less than $5 \%$, meaning that there is a relationship among the study variables as shown in table 5 .

Table 5. Kao residual cointegration test.

\begin{tabular}{lll}
\hline ADF & t-Statistic & Prob. \\
\hline (Individual intercept) & & \\
\hline Equation (1) & -2.717531 & 0.0033 \\
\hline
\end{tabular}

Source: Authors calculation using Eviews.

\subsection{Model Estimation}

The results of the panel stationarity and cointegration tests are the main reason that prevents the authors to estimate the model directly with the ordinary least squares (OLS). Since the variables are cointegrated, the long-run equilibrium parameters can be estimated by using the Vector Error Correction Model (VECM) technique to avoid the problem of spurious regression. The results of applying (VECM) are shown in table 7. According to the previous studies, there are different types of factors that have a potential impact on the economic growth in the Arab countries, therefore, his study analyzed the potential role of some of these factors.

\subsubsection{Lag Length Criteria}

In order to test the lag length criteria for equation 1 , table 6 has been used to identify the necessary lag intervals. The results of such a table show that the optimal lag of one.

\subsubsection{Vector Error Correction Model Estimates}

Correspondingly, based on the speed of the adjustment coefficient; the results in table 7 show that all political indicators have the expected negative sign and statistically significant, meaning that there is a long run causality running from each indicator to the economic growth. Model 5 and 4 which contains $\mathrm{CC}$ and RL respectively, have the highest impact on the economic growth as $74 \%$ and $72 \%$ of the variation from the long run equilibrium will be corrected in each year. While PV and VA approximately have the same influence level on the dependent variable as appeared in model 2 and 1, where both deviations will be modified by $63 \%$. Finally, the results of model 3 show that RQ has the lowest impact on economic growth; with just $33 \%$ of the correction will be done during the year.

\subsubsection{Results of Diagnostic Tests}

The results of table 8 show that the five models have passed the diagnostic tests as the p- values of each test was above $5 \%$ with statistically insignificant, except the first model as the p-value of the normality tests revealed that the data is not normally distributed. Also, model 3 and 4 both suffer from the Autocorrelation problem as their p-values are statistically significant; (0.0224) and (0.0327) respectively. 
Table 6. Lag length criteria.

\begin{tabular}{|c|c|c|c|c|c|c|}
\hline$\overline{L a g}$ & $\log L$ & LR & FPE & $\overline{\text { AIC }}$ & $\overline{\mathrm{SC}}$ & HQ \\
\hline 0 & -1503.693 & NA & $2.82 \mathrm{e}+09$ & 44.46155 & 44.72267 & 44.56501 \\
\hline 1 & -794.0176 & 1231.495 & $16.12845^{*}$ & 25.47110 & $27.82117^{*}$ & $26.40227^{*}$ \\
\hline 2 & -731.0379 & $94.46943 *$ & 17.89827 & 25.50112 & 29.94013 & 27.25999 \\
\hline 3 & -668.4229 & 79.18955 & 22.82090 & 25.54185 & 32.06982 & 28.12843 \\
\hline 4 & -594.4296 & 76.16964 & 26.00753 & $25.24793 *$ & 33.86484 & 28.66221 \\
\hline
\end{tabular}

* The optimal lag interval for the equation.

LR: sequential modified LR test statistic (each test at 5\% level).

FPE: Final prediction error.

AIC: Akaike information criterion.

SC: Schwarz information criterion.

HQ: Hannan-Quinn information criterion.

Table 7. Vector Error Correction Estimates.

Model 1: The impact of the voice and accountability on the economic growth in the long run

\begin{tabular}{llllll}
\hline & ECT & D(GGDP) & D(LGFCF) & D(LHC) & D(VA) \\
\hline Coefficient & -0.625544 & 0.184281 & 2.932334 & -34.51775 & 0.021891 \\
S.E & $(0.14453)$ & $(0.13127)$ & $(2.64075)$ & $(19.4589)$ & $(0.05240)$ \\
t-statistics & {$[-4.32822]$} & {$[1.40388]$} & {$[1.11042]$} & {$[-1.77388]$} & {$[0.41775]$} \\
\hline
\end{tabular}

Model 2: The impact of the political stability and the absence of violence on the economic growth in the long run

\begin{tabular}{llllll}
\hline & ECT & D(GGDP) & D(LGFCF) & D(LHC) & D(PV) \\
\hline Coefficient & -0.627635 & 0.179051 & 2.945371 & -38.11682 & 0.007913 \\
S.E & $(0.13934)$ & $(0.12784)$ & $(2.64600)$ & $(19.8756)$ & $(0.05160)$ \\
t-statistics & {$[-4.50439]$} & {$[1.40063]$} & {$[1.11314]$} & {$[-1.91777]$} & {$[0.15334]$} \\
\hline
\end{tabular}

Model 3: The impact of the regulatory quality on the economic growth in the long run

\begin{tabular}{llllll}
\hline & ECT & D(GGDP) & D(LGFCF) & D(LHC) & D(RQ) \\
\hline Coefficient & -0.328751 & -0.063922 & 4.130470 & -0.007091 & -35.73920 \\
S.E & $(0.09088)$ & $(0.11765)$ & $(2.75232)$ & $(20.2577)$ & $(0.07199)$ \\
t-statistics & {$[-3.61748]$} & {$[-0.54331]$} & {$[1.50072]$} & {$[-1.76423]$} & {$[-0.09849]$} \\
\hline
\end{tabular}

Model 4: The impact of the rule of law on the economic growth in the long run

\begin{tabular}{|c|c|c|c|c|c|}
\hline & ECT & D(GGDP) & D(LGFCF) & D(LHC) & D(RL) \\
\hline Coefficient & -0.720504 & 0.131871 & 4.791449 & -33.14890 & -0.178448 \\
\hline S.E & $(0.13135)$ & $(0.11565)$ & $(2.42105)$ & (17.5355) & $(0.07425)$ \\
\hline t-statistics & {$[-5.48540]$} & [1.14023] & [1.97908] & {$[-1.89039]$} & {$[-2.40336]$} \\
\hline
\end{tabular}

Model 5: The impact of the control of corruption on the economic growth in the long run

\begin{tabular}{|c|c|c|c|c|c|}
\hline & ECT & D(GGDP) & D(LGFCF) & D(LHC) & $\mathrm{D}(\mathrm{CC})$ \\
\hline Coefficient & -0.736143 & 0.154678 & 4.595805 & -45.92820 & -0.024917 \\
\hline S.E & $(0.14401)$ & $(0.12366)$ & $(2.55754)$ & $(19.2471)$ & $(0.05123)$ \\
\hline t-statistics & {$[-5.11183]$} & [ 1.25085$]$ & [ 1.79696$]$ & {$[-2.38624]$} & {$[-0.48640]$} \\
\hline
\end{tabular}

Source: Authors calculation using Eviews.

Table 8. Summary of the Diagnostic Tests.

Model 1: The impact of the voice and accountability on the economic growth in the long run

\begin{tabular}{ll}
\hline Diagnostic Tests & Chi -sq \\
Autocorrelation, LM test & $23.96123(0.0904)$ \\
Normality Test & $47.00266(0.0000)$ \\
Heteroskedisiticty, Whit test (no cross terms) & $161.7472(0.8318)$ \\
Heteroskedasticity, Whit test (with cross terms) & $538.2713(0.5129)$ \\
\hline Model 2: The impact of the political stability and the absence of violence on the economic growth in the long run \\
\hline Autocorrelation, LM test & $29.23552(0.0224)$ \\
Normality Test & $9.453514(0.0507)$ \\
Heteroskedasticity, Whit test (no cross terms) & $196.7692(0.1860)$ \\
Heteroskedasticity, Whit test (with cross terms) & $568.4495(0.1918)$ \\
\hline
\end{tabular}


Model 3: The impact of the regulatory quality on the economic growth in the long run

\begin{tabular}{ll}
\hline Autocorrelation, LM test & $22.92640(0.1157)$ \\
Normality Test & $5.685359(0.2239)$ \\
Heteroskedasticity, Whit test (no cross terms) & $190.2175(0.2865)$ \\
Heteroskedasticity, Whit test (with cross terms) & $568.9537(0.1878)$ \\
\hline Model 4: The impact of the rule of law on the economic growth in the long run & $18.82856(0.2777)$ \\
\hline Autocorrelation, LM test & $10.50875(0.0327)$ \\
Normality Test & $177.6939(0.5346)$ \\
Heteroskedasticity, Whit test (no cross terms) & $563.2979(0.2360)$ \\
Heteroskedasticity, Whit test (with cross terms) & \\
\hline Model 5: The impact of the control of corruption on the economic growth in the long run & $18.14825(0.3153)$ \\
\hline Autocorrelation, LM test & $8.279428(0.0819)$ \\
Normality Test & $192.7939(0.2439)$ \\
Heteroskedasticity, Whit test (no cross terms) & $532.2620(0.5856)$ \\
\hline Heteroskedasticity, Whit test (with cross terms) & \\
\hline
\end{tabular}

Source: Authors calculation using Eviews. *Values between brackets are p-values.

\section{Conclusion}

The main goal of this study is to empirically test if the political instability has an impact on the economic growth, and which indicator has the highest impact on the growth, for Egypt, Jordan, Lebanon, and Tunisia, during the period $1996-$ 2016. Consequently, the study looks deeply into more related elements by exploring the main factors that determine the dependent variable. The study used the growth of GDP per capita as a proxy for economic growth.

The results of this study and based on the above discussion show the strong relationship between political instability and economic growth. The rationale behind this argument, based on the fact that is a country with a stabilized policy will have a high degree of steady economic foundations and firms. In addition to their creditability in all the related business and financial interactions, by doing so, this will decrease the volatility and doubt to any upcoming organizations and policymakers, therefore the private sector in such a country will be controlled with a strong desire of investing there, also they will increase utilizing the accumulation of their physical capital, as a result, this will lead to economic growth in the long run and low inflation rates. These results are consistent with the outcomes of the majority of the literature.

\section{References}

[1] Sidamor, Z., Lemtaouch, L., \& Bensouici, H. (2016). The Economic Consequences of the Political Instability in Arab Region. Procedia-Social and Behavioral Sciences, 219, 694-699.

[2] Barro, R. J. (2013). Education and Economic Growth. ANNALS OF ECONOMICS AND FINANCE, 14 (2), 277-304.

[3] De Mesquita, B. B., Morrow, J. D., Siverson, R. M., \& Smith, A. (2000). Political institutions, political survival, and policy success. In Governing for prosperity (pp. 59-84). Yale University Press.

[4] Alesina, A., Özler, S., Roubini, N., \& Swagel, P. (1996).
Political instability and economic growth. Journal of Economic growth, 1 (2), 189-211.

[5] Alesina, Alberto and Roberto Perotti 1996. "Income Distribution, Political Instability, and Investment", European Economic Review 40, 1203-1228.

[6] Feng, Y. (1997). Democracy, Political Stability, and Economic Growth. British Journal of Political Science, 391-418.

[7] Campos, N. F., \& Nugent, J. B. (2002). Who is afraid of political instability? Journal of Development Economics, 67 (1), 157-172.

[8] Zureiqat, H. M. (2005). Political instability and economic performance: a panel data analysis.

[9] Farida, M., \& Ahmadi-Esfahani, F. Z. (2008). Corruption and economic growth in Lebanon. In 52nd Annual Australian Agricultural and Resource Economics Society Conference paper.

[10] Aisen, A., \& Veiga, F. J. (2013). How does political instability affect economic growth? European Journal of Political Economy, 29, 151-167.

[11] Rehman, A. A. (2015). Macroeconomic Instability and Its Impact on Gross Domestic Product: An Empirical Analysis of Pakistan. National College of Business Administration and Economics, 1-24.

[12] Abdelkader, H. E. (2015). Political Instability, Uncertainty, Democracy, and Economic Growth in Egypt. Working papers.

[13] Matta, S., Appleton, S., \& Bleaney, M. (2016). The impact of the Arab Spring on the Tunisian economy. The World Bank Economic Review, lhw059.

[14] Sweidan, O. D. (2016). Political Instability and Economic Growth: Evidence from Jordan. Review of Middle East Economics and Finance, 12(3), 279-300.

[15] Kaplan, E. A., \& Akçoraoğlu, A. (2017). Political Instability, Corruption, and Economic Growth: Evidence from a Panel of OECD Countries. Business and Economics Research Journal, $8(3), 363-377$.

[16] Aisen, A., \& Veiga, F. J. (2006). Does political instability lead to higher inflation? A panel data analysis. Journal of Money, Credit, and Banking, 38 (5), 1379-1389. 
[17] Khan, S. U., \& Saqib, O. F. (2011). Political instability and inflation in Pakistan. Journal of Asian economics, 22 (6), 540-549.

[18] Najaf, R. N. (2016). Impact of political stability on the macroeconomic variables and FDI of Pakistan. Developing Countries Studies, 109-115.

[19] Asiedu, E. (2006). Foreign direct investment in Africa: The role of natural resources, market size, government policy, institutions and political instability. The World Economy.

[20] Tosun, M. U., Guran, M. C., \& Ulucan, A. (2008). The Political Instability, Investment Profile and the Macroeconomic Performance of the Middle East \& North Africa (MENA) Region. Problems and Perspectives in Management, 31-38.

[21] Campos, N. F., \& Nugent, J. B. (2003). Aggregate investment and political instability: an econometric investigation. Economica, 70 (279), 533-549.
[22] Frynas, J. G. (1998). Political instability and business: focus on Shell in Nigeria. Third World Quarterly, 19 (3), 457-478.

[23] Kaufmann, D., Kraay, A., \& Mastruzzi, M. (2011). The worldwide governance indicators: methodology and analytical issues. Hague Journal on the Rule of Law, 3 (2), 220-246.

[24] Amadeo, K. (2018). Economic growth, its measurements, causes, and effects. Thebalance. Retrieved from https://www.thebalance.com/what-is-economic-growth-33060 14.

[25] Modigliani, F., \& Cohn, R. A. (1979). Inflation, rational valuation and the market. Financial Analysts Journal, 24-44.

[26] World Bank. International Economics Dept. Development Data Group. (2005). World development indicators. World Bank.

[27] Investment. (2018). Financial Dictionary. Retrieved from: https://financial-dictionary.thefreedictionary.com/investment. 